\title{
Los géneros narrativos audiovisuales como fuente de "inspiración"
}

\section{Audiovisual narrative genres as a source of 'inspiration'}

Fechas | En edición: 30/11/2020 - Publicación final: 01/01/2021

\section{Sara REBOLLO-BUENO}

Universidad de Sevilla. España. srebollo@us.es

\section{Géneros narrativos audiovisuales en publicidad}

Coordinadores: Jorge David Fernández Gómez y

María del Mar Rubio-Hernández.

Madrid: TECNOS (Grupo ANAYA), 2019.

270 páginas

ISBN: 978-84-309-7659-1

\section{Resumen}

Géneros narrativos audiovisuales en publicidad hace un recorrido por los diferentes géneros narrativos audiovisuales, pasando por las obras más destacadas y sus marcas de género. La obra es esencial para explicar la instrumentalización de los géneros narrativos en el proceso de creación publicitario.

\section{Palabras clave}

Géneros narrativos; Publicidad; Cultura de masas; Creatividad

\begin{abstract}
Géneros narrativos audiovisuals en publicidad takes a look at the different audiovisual narrative genres, making a journey through the most outstanding works and their genre marks The work is essential to explain the instrumentalization of narrative genres in the process of advertising creation.
\end{abstract}

\section{Keywords}

Narrative genres; Advertising; Mass culture; Creativity. 
Los procesos creativos parecen ocupar un lugar oscuro dentro de la literatura publicitaria. Oscuro porque no hay atrevimientos académicos que sean capaces de abordar este tema tan abstracto y complicado. Solo hay una cosa clara: las fuentes de creatividad no son inspiraciones que aparecen de la nada. Como bien saben los publicistas, la creatividad es una característica que se pone en valor y, en la mayoría de las ocasiones, marca la diferencia entre diferentes campañas y marcas. La ansiada búsqueda de dicha creatividad lleva a preguntarse cómo conseguirla. Géneros narrativos audiovisuales en publicidad explica cómo las ideas nuevas nacen de la mezcla y la asimilación de conceptos e ideas previos. De hecho, en las propias palabras del famoso autor del prólogo, Toni Segarra: "Nada surge de la nada. Conocer los mapas permite salirse de las rutas habituales" (pp. 11).

Los coordinadores de este libro, Jorge David Fernández Gómez y María del Mar Rubio-Hernández, ofrecen al lector un recorrido por los diferentes géneros narrativos y cómo estos se instrumentalizan en el ámbito publicitario, en especial el creativo, tanto como fuente de inspiración como para el desarrollo narrativo de las marcas. La obra está compuesta por quince capítulos, profundizando cada uno de ellos en un género en particular. De la mano de diferentes teóricos, el lector puede discernir los distintos géneros, gracias a las marcas de género que los autores desglosan y desarrollan, así como al análisis de diferentes anuncios que beben de estos géneros audiovisuales.

El primer capítulo de Géneros narrativos audiovisuales en publicidad está escrito por los propios coordinadores, en el cual aportan delimitaciones conceptuales y apuntes esenciales sobre la cultura de masas, la publicidad y los géneros como una de las fuentes de "inspiración" para el proceso de creación publicitaria. Tras esto, Jesús Jiménez-Varea explica el afán por teorizar sobre los géneros narrativos, se adentra en la industria cultural y deriva en la importancia de los géneros como una buena baza para productores, así como una forma de llegar a los receptores. Tras estos dos capítulos introductorios de carácter general, los capítulos posteriores se dedican a un género narrativo específico, siguiendo una misma estructura. Antonio Pineda dedica el tercer capítulo a la ciencia ficción con marcas de género como "el viaje en el tiempo", "robots y seres artificiales" o "las mutaciones", hasta llegar a la pieza publicitaria de Audi: The Invisible Man. Los superhéroes también encuentran su hueco en esta obra gracias a Miguel Ángel Pérez Gómez. El autor expone cómo esas características extraordinarias de estos personajes acaban por traspasarse a las marcas a través de la publicidad: nos explica el caso de Snickers.

Jorge David Fernández Gómez profundiza en el horror, desde sus marcas de género hasta sus personajes más icónicos como Nosferatu, Frankestein o los hombres lobos, poniendo como ejemplo la miniserie 13 miedos de Doritos. Una campaña que se adentra en los miedos que habitan en nuestro subconsciente y son explotados publicitariamente. Tras el horror, se aventura el terror, donde de la mano de Víctor Hernández-Santaolalla, se explica cómo este género protagonizado por asesinos en serie y maníacos también tienen cabida en la publicidad. El autor hace un recorrido por obras como Piscosis (Psycho, Alfred Hitchcock, 1960) o Verónica (Paco Plaza, 2017), destacando el uso de sus características por marcas como Securitas Direct o GEICO. En el siguiente capítulo, Irene Raya Bravo se adentra en el género de la fantasía, marcado por los héroes, las heroínas, la magia y la hechicería. La autora desarrolla cómo todos estos componentes llegan a la publicidad bajo la línea de Campbell pero con cambios tan contundentes como que la princesa se salva a sí misma en los anuncios de GHD: Twisted Fairytales. Las marcas del Western se pueden encontrar en el octavo capítulo gracias a Adrián Huici. Este género forma parte de la construcción identitaria estadounidense con la representación de sherifsf y duelos, los cuales se acaban transmitiendo a marcas como Marlboro y su famoso vaquero.

Alberto Hermida presenta el cine negro, caracterizado por "el destino inexorable [...] una carretera sin salida, sin futuro ni esperanza" (pp. 165). Esto al principio puede parecer completamente antagónico a lo que es o busca reflejar la publicidad. No obstante, el autor explica cómo se utiliza en pro de los objetivos publicitarios, en el caso específico de la marca danesa Café Noir de Merrild. El género policíaco también supone una fuente de utilidad para la creatividad publicitaria. De hecho, Sergio Cobo Durán, el autor, hace un recorrido por las comisarías de policía del audiovisual para finalizar en el análisis de una pieza de advertainment de Philips. Mónica Barrientos-Bueno demuestra cómo el género histórico también participa en la creación publicitaria. La publicidad bebe de esos personajes, situaciones y tramas que la propia Historia otorga. Un ejemplo en el que profundiza la autora es la histórica tregua por Navidad en 1914 durante la Primera Guerra Mundial, momento histórico que se refleja en el spot de la campaña navideña de Sainsbury's.

En el capítulo doce, María del Mar Rubio-Hernández trae la comedia a este recorrido por géneros audiovisuales. Un género narrativo, explica la autora, bastante recurrente en el ámbito publicitario; un recurso que ha recibido y puede recibir múltiples formas desde diferentes conceptos creativos. RubioHernández lo ejemplifica con la campaña "Las cosas como son" de Sprite. El siguiente capítulo viene de la mano de Ángeles Martínez-García y María del Mar Ramírez Alvarado, profundizando en el género dramático. A pesar de la amplitud de este género, las autoras describen las características del mismo y 
sus diferentes variantes, dándoles la posibilidad de mostrar sus facetas de aplicabilidad en publicidad. Analizan el caso de la campaña navideña de 2014 de Loterías y Apuestas del Estado. El siguiente capítulo de este recorrido por los géneros audiovisuales está dedicado al género musical. David Selva-Ruiz destaca la tendencia a exhibir una visión idealizada de la realidad, lo cual encaja a la perfección con las tendencias estratégicas publicitarias. El autor se adentra en cómo sacarle partido a este género desde el proceso creativo publicitario, materializándolo con el ejemplo de "Despedido" de Coca-Cola. En el último capítulo de la obra, Virginia Guarinos y Carmen Costa-Sánchez se adentran en las marcas de género de la sensualidad y el erotismo narrativos. Las autoras explican el uso del cuerpo, el deseo y la seducción en la publicidad, como en los casos de Magnum y Valor.

En definitiva, Géneros narrativos audiovisuales en publicidad aporta un recorrido por los diferentes géneros narrativos que tienen vínculos especiales con la publicidad y que, por tanto, son imprescindibles para entender tanto el proceso creativo publicitario, como para analizar la recepción de este discurso de masas que es la publicidad. Cabe mencionar que esta obra consigue alumbrar parte de ese vacío que existe en la literatura publicitaria sobre el proceso creativo. Su relevancia no yace solamente en su interés académico al ser un manual útil en la enseñanza y la investigación, sino que también se convierte en una obra esencial en el marco profesional de la publicidad. 